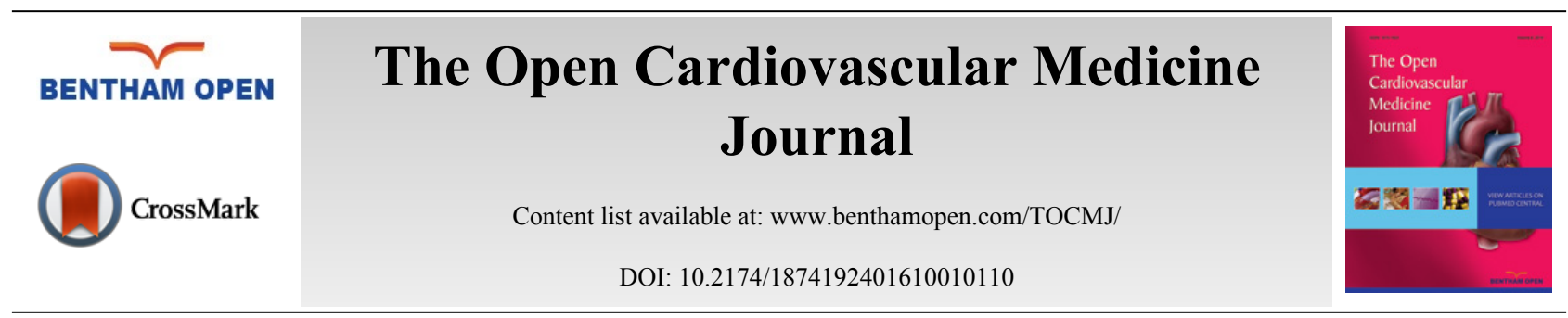

\title{
Stroke Prevention in Atrial Fibrillation and Valvular Heart Disease
}

\author{
Saad Ahmad* and Heath Wilt \\ Division of Cardiovascular Health and Disease, University of Cincinnati College of Medicine, Cincinnati, OH, USA
}

Received: August 22, 2015

Revised: September 20, 2015

Accepted: October 22, 2015

\begin{abstract}
There is a clinically staggering burden of disease stemming from cerebrovascular events, of which a majority are ischemic in nature and many are precipitated by atrial fibrillation (AF). AF can occur in isolation or in association with myocardial or structural heart disease. In the latter case, and when considering health at an international level, congenital and acquired valve-related diseases are frequent contributors to the current pandemic of AF and its clinical impact. Guidelines crafted by the American Heart Association, American College of Cardiology, European Society of Cardiology and Heart Rhythm Society underscore the use of vitamin $\mathrm{K}$ antagonists (VKAs) among patients with valvular heart disease, particularly in the presence of concomitant $\mathrm{AF}$, to reduce the risk of ischemic stroke of cardioembolic origin; however, the non-VKAs, also referred to as direct, target-specific or new oral anticoagulants (NOACs), have not been actively studied in this particular population. In fact, each of the new agents is approved in patients with AF not caused by a valve problem. The aim of our review is to carefully examine the available evidence from pivotal phase 3 clinical trials of NOACs and determine how they might perform in patients with AF and concomitant valvular heart disease.
\end{abstract}

Keywords: Atrial fibrillation, ischemic stroke, oral anticoagulants, valve-related heart disease.

\section{INTRODUCTION}

Approximately 795,000 persons in the United States (US) experience a new or recurrent cerebrovascular event each year [1]. A majority of events are ischemic in nature. It is well known that patients with valvular heart disease are at heightened risk for ischemic stroke, particularly those with mitral stenosis and underlying atrial fibrillation (AF) or atrial flutter $[2,3]$.

\section{Traditional Perspective of Valvular Heart Disease and AF}

Rheumatic heart disease involving the mitral valve causes inflammation and fibrosis with disruption of the atrial architecture. There is increased left atrial pressure that contributes to left atrial dilation and increased wall stress. These acquired local conditions are thought to represent predisposing factors to the development of AF [4, 5].

While non valvular atrial fibrillation (NVAF) is known to increase the risk for ischemic stroke by 5-fold, the risk is even greater among patients with mitral stenosis, increasing up to 17-fold [6]. Approximately two-thirds of patients with valvular atrial fibrillation (VAF) (mitral stenosis) who survive a first ischemic stroke experience a second event in the subsequent decade. Half of the events occur in the first year. A retrospective study by Walker and colleagues reported that patients with rheumatic mitral stenosis in sinus rhythm had an incidence of $8 \%$ per year of an embolic event; this increased to $31.5 \%$ in patients with concomitant AF. Patients with rheumatic valvular disease characterized predominantly by mitral regurgitation were also at heightened risk for a cardioembolic event, even among those in sinus rhythm who had an incidence of $7.7 \%$ per year, increasing to $22 \%$ in those with AF [7].

While there have been no large randomized clinical trials to demonstrate the effectiveness of anticoagulation for thrombo-prophylaxis in patients with rheumatic valvular heart disease and atrial fibrillation, observational studies and

\footnotetext{
* Address correspondence to this author at the University of Cincinnati, Division of Cardiovascular Diseases, 231 Albert Sabin Way, Academic Health Center, Medical Sciences Building, Mail Location MLB 052, Cincinnati, OH 45267-0542, USA; Tel: (617) 780 7354; Fax: (513) 558 1255; Email: ahmadsm@ucmail.uc.edu
} 
retrospective analyses of patients with mitral stenosis do offer support for treatment. In a study by Fleming and colleagues, patients not anticoagulated had an embolic event incidence of $25 \%$ per year; in contrast, patients receiving anticoagulation, primarily a VKA, had $0.8 \%$ patient-year incidence of embolic events and a $0 \%$ recurrence rate [8]. A review of 254 patients with VAF reported that the incidence of an embolic event was 8 times greater in patients not receiving anticoagulation, versus those treated with an oral anticoagulant [9]. In 1977, the Joint Committee for Stroke published a statement that reviewed 11 studies evaluating thrombo-prophylaxis with anticoagulant therapy in patients with rheumatic mitral disease; they recommended anticoagulation in patients with rheumatic heart disease, particularly those with AF and a history of ischemic stroke [10].

\section{Contemporary Perspective of Valvular Heart Disease and AF}

AF currently affects over 2 million persons in the US, and this number is projected to increase to 10 million by the year 2050 [11]. The total number may actually be much higher, as nearly 50\% of persons with AF do not experience signs or symptoms of the arrhythmia. AF is believed to account for at least 10-12\% of all ischemic strokes [12, 13] and the risk increases steadily with age and other common conditions, including systemic hypertension.

The AHA/ACC/HRS Guideline for the Management of Patients With Atrial Fibrillation has defined AF in the presence of rheumatic heart disease or either mechanical or bioprosthetic valve in the mitral position as VAF [14, 15]. The European Society of Cardiology Guidelines also determined VAF to be present with concomitant rheumatic heart disease (primarily mitral stenosis) or a prosthetic heart valve [16].

\section{Clinical Trials of New Oral Anticoagulants}

The development of new oral anticoagulants (NOACs) as an alternative to VKAs in patients with AF focused on those without valvular heart disease (NVAF) (Table 1). This decision was reflective of a changing landscape in Europe and North America, with a declining incidence and overall prevalence of rheumatic heart disease and rapidly increasing number of persons with AF at risk for ischemic stroke. It also acknowledged the wide phenotypic variability for cardioembolic stroke risk with mild, moderate and severe rheumatic mitral stenosis. Despite the clear decision to perform pivotal trials in patients with NVAF, patients with valvular heart disease were enrolled.

Table 1. Summary of the trials involving the Novel Oral Anticoagulants for treatment of Non Valvular Atrial Fibrillation, with their respective definition of valvular disease and the out comes.

\begin{tabular}{|c|c|c|c|}
\hline Drug & Trial & Definition of valvular disease & Outcomes \\
\hline Apixaban & AVERROES [32,33] & $\begin{array}{c}\text { Valvular heart disease requiring surgery, } \\
\text { including prosthesis valves }\end{array}$ & $\begin{array}{c}\text { Apixaban reduced the risk of stroke or systemic } \\
\text { embolism without significant bleeding risk or } \\
\text { intracranial hemorrhage in NVAF. }\end{array}$ \\
\hline Apixaban & ARISTOTLE-AF [20,29] & $\begin{array}{c}\text { Prosthetic valve or clinically significant } \\
\text { (moderate or severe) mitral stenosis }\end{array}$ & $\begin{array}{c}\text { Apixaban was superior to warfarin in reducing stroke } \\
\text { and systemic embolism in NVAF. }\end{array}$ \\
\hline Dabigatran & RE-LY [19,34] & $\begin{array}{c}\text { Prosthetic valve or hemo-dynamically relevant } \\
\text { valve disease }\end{array}$ & $\begin{array}{c}\text { Dabigatran had lower rates of stroke or systemic } \\
\text { embolism but similar rates of hemorrhage as warfarin } \\
\text { when dosed at 150mg twice a day in NVAF }\end{array}$ \\
\hline Edoxaban & ENGAGE-AF-TIMI 48 & $\begin{array}{c}\text { Moderate or severe mitral stenosis, mechanical } \\
\text { prosthetic valves }\end{array}$ & $\begin{array}{c}\text { Edoxaban was non inferior to warfarin at both doses for } \\
\text { prevention of stroke or systemic embolism in NVAF }\end{array}$ \\
\hline Edoxaban & $\begin{array}{c}\text { ENSURE-AF (actively } \\
\text { enrolling) [35] }\end{array}$ & $\begin{array}{c}\text { Mitral stenosis or rheumatic disease, mechanical } \\
\text { prosthetic valve }\end{array}$ & $\begin{array}{c}\text { Currently underway } \\
\text { prosthetic valve }\end{array}$ \\
\hline Rivaroxaban & ROCKET-AF [17, 18] & $\begin{array}{c}\text { Hemodynamically significant mitral stenosis or } \\
\text { prevention of stroke and systemic embolism in NVAF }\end{array}$ \\
\hline
\end{tabular}

In order to better understand the spectrum of valvular heart disease captured in the NOAC registration trials, one must carefully review individual study exclusion criteria. The Rivaroxaban Once Daily Oral Direct Factor Xa Inhibition Compared with Vitamin K Antagonism for Prevention of Stroke and Embolism Trial in Atrial Fibrillation (ROCKET AF) excluded patients with prosthetic heart valves and those with hemodynamically significant mitral stenosis [17]. In contrast, the Randomized Evaluation of Long-Term Anticoagulation (RE-LY) trial excluded patients with prosthetic heart valves and those with hemodynamically significant native valvular heart disease, but did not distinguish between the aortic and mitral valves $[18,19]$. The Apixaban for Reduction in Stoke and Other Thromboembolic Events in Atrial Fibrillation (ARISTOTLE) trial excluded patients with moderate-to-severe mitral stenosis and those with prosthetic heart valve [20]. The Apixaban versus Acetylsalicylic Acid to Prevent Stroke in Atrial Fibrillation Patients Who Have Failed or Are Unsuitable for Vitamin K Antagonist Treatment (AVERROES) trial excluded patients with valvular heart disease that was severe enough to require surgery. Perhaps the most inclusionary of the phase 3 trials, the Effective 
Anticoagulation with Factor Xa Next Generation in Atrial Fibrillation-Thrombolysis in Myocardial Infarction 48 (ENGAGE AF-TIMI 48) trial, did not exclude patients with either bioprosthetic valves or those who had previously undergone a valve repair $[21,22]$.

Table 2. Novel Oral Anticoagulant trials with their defined respective safety and efficacy endpoint.

\begin{tabular}{|c|c|c|c|}
\hline Drug & Trial & Primary safety outcome & Primary efficacy endpoint \\
\hline Apixaban & AVERROES [32,33] & Time to major bleeding & Time to stroke or systemic thromboembolus \\
\hline Apixaban & ARISTOTLE-AF [20,21] & Time to major bleeding & Time to stroke or systemic thromboembolus \\
\hline Dabigatran & RE-LY [19,34] & Major bleeding & Stroke or systemic thromboembolus \\
\hline Edoxaban & ENGAGE-AF-TIMI 48 [22] & Major bleeding & Time to stroke or systemic thromboembolus \\
\hline Rivaroxaban & ROCKET-AF [17, 18] & Major and nonmajor clinically relevant bleeding & Stroke or systemic thromboembolus \\
\hline
\end{tabular}

\section{RE-LY Trial}

In the RE-LY trial, a direct thrombin inhibitor, dabigatran etexilate, was compared at two fixed doses with warfarin in a blinded study. The primary outcome was defined as either cerebral or systemic embolism. At 110mg dose, dabigatran was found to be non-inferior to warfarin for the rate of primary outcome. At the higher dose of $150 \mathrm{mg}$, dabigatran was superior to warfarin for primary outcomes risk reduction [23].

In this trial, patients that were excluded had either a history of "severe valvular disorders," defined by prosthetic valve or hemodynamically relevant valve disease $[19,23]$. Despite the exclusion criteria, there were patients with valvular disease that were included in the trial. In total, $21.8 \%$ percent of the patients enrolled in the RE-LY trial had some form of valvular heart disease that did not exclude them from participation; only $1.1 \%$ of them had mild mitral stenosis. Additionally, a subgroup analysis compared the overall effects of dabigatran with warfarin in patients with and without symptomatic heart failure (defined as the presence of NYHA class II or higher symptoms in the six months before screening with a prior admission for congestive heart failure) [24]. In this analysis, 26.2\% of participants in the symptomatic heart failure group and $20.1 \%$ in the group without NYHA class II or greater heart failure, had "valvular heart disease" [24]. The study showed no significant outcome differences with either dabigatran or warfarin in this subset of patients.

While the RE-LY trial illustrates the benefits of dabigatran for thromboembolism protection, the Randomized Phase II Study to Evaluate the Safety and Pharmacokinetics of Oral Dabigatran Etexilate in Patients after Heart Valve Replacement (RE-ALIGN) is perhaps the most direct evaluation of a NOAC versus VKA for patients with valvular heart disease - in this particular case, mechanical prosthetic valves [25].

The study compared anticoagulation with dabigatran against warfarin in patients with either mechanical aortic or mitral valve replacement (AVR, MVR) [25]. Patients who had undergone either AVR or MVR within 7 days, or at least 3 months earlier, were then randomly assigned to receive warfarin (dosed to an INR of 2 to 3 or 2.5 to 3.5 , on the basis of thromboembolic risk) or dabigatran (dosed to obtain a trough plasma level of at least $50 \mathrm{ng}$ per milliliter). The study was discontinued due to the high thromboembolic and bleeding events among patients in the dabigatran group. The composite of stroke, transient ischemic attack, systemic embolism, myocardial infarction, or death occurred in 15 patients $(9 \%)$ in the dabigatran group and 4 patients $(5 \%)$ in the warfarin group (hazard ratio in the dabigatran group, 1.94; $95 \%$ confidence interval $[\mathrm{CI}], 0.64$ to $5.86 ; P=0.24)$; thromboembolic events were higher in the group started on dabigatran within 7 days of MVR. Additionally, all cases of valve thrombosis detected in clinically asymptomatc patients were reported in the dabigatran group (3\%) [25].

Based on the available data, dabigatran for patients with mechanical valves cannot not be supported, showing no benefit and an excess risk; however, the RE-ALIGN trial did generate a dialogue and series of questions to better understand the findings that included a lack of uniform aspirin use and reported mean time within the pre-defined target drug range of approximately 50\% [26]. The latter suggests changes in dabigatran pharmacokinetics in the setting of cardiac surgery or the dynamics of blood flow and metabolism after heart valve surgery. Whether similar properties should be expected in the setting of trans-aortic valve implantation (TAVR) will require further investigation.

\section{ROCKET AF Trial}

In a multicenter randomized double-blinded, double-dummy trial, rivaroxaban was compared against warfarin for risk reduction in NVAF. Patients requiring anticoagulation for any other reason were excluded. The primary end point was stroke and systemic embolism. The hazard ratio was lower in the rivaroxaban group at 0.79 (95\% CI 0.66-0.96) [17]. The event rates for disabling stroke and stroke with leading to death were lower in the rivaroxaban group 
compared to the warfarin group [27]. Patients were excluded from the clinical trial if they had active endocarditis, atrial myxoma or prosthetic valves. The trial did permit patients with non-critical valvular heart disease, annuloplasty, with or without prosthetic ring, commissurotomy and/or valvuloplasty to be enrolled $[17,18]$.

A post-hoc analysis showed that $14.1 \%$ of the 14,171 patients enrolled in ROCKET AF had significant valvular disease (SVD) and were evaluated by intention- to- treat and in the safety analysis [28]. Rheumatic valve disease was identified in $3.2 \%$ of the patients, mitral regurgitation, the most frequent valvular disease present, was present in in $89.6 \%$ of the patients. Patients with SVD had more comorbidity, but there was no significant difference in patients on warfarin in terms of their CHADS2 and HASBLED scores. The end points, rate of stroke or systemic embolism, were similar in the rivaroxaban and warfarin groups, consistent with the original trial, HR, 0.89 (95\% CI, 0.75-1.07), interaction $\mathrm{P}$ value for SVD was 0.76 [17, 18]. Major and non-major clinically relevant bleeding were higher in the SVD patients compared to those without SVD. In patients with SVD, there was a higher incidence of bleeding in the rivaroxaban group (19.8\%) compared to those on warfarin $(16.8 \%)$ with HR $1.25,(95 \%$ CI, $1.05-1.49)$ but there was no significant difference reported in patients without SVD, P value for interaction for SVD and treatment was 0.034 . Consistent with the overall findings from ROCKET AF, the rate of ICH was lower in patients randomized to rivaroxaban versus those receiving warfarin with or without SVD [28].

\section{ARISTOTLE Trial}

Apixaban is a direct Xa inhibitor that was compared to warfarin in NVAF in a double-blinded, double-dummy randomized trial. Apixaban proved to be superior to warfarin in the ARISTOTLE trial for the primary efficacy out come, stroke or systemic embolism. The study also showed the primary safety outcome of major bleeding, morbidity with clinically relevant non-major bleeding and mortality to be significantly lower with apixaban [21, 29].

Patients with concomitant valvular heart disease of moderate or severe mitral stenosis were excluded from this trial, as were patients requiring anticoagulation for indications other than atrial fibrillation, such as a history of prosthetic heart valve $[20,21,29]$. A subanalysis of the ARISTOTLE trial identified $26.4 \%$ of the patients enrolled as having some component of significant valvular heart disease other than mechanical heart valve and clinically significant mitral stenosis. This group of patients was comprised of those having prior valve surgery and/or echocardiographic features of moderate valve disease. Mitral stenosis was present in $2.7 \%$ of the patients, while moderate mitral regurgitation represented the predominant valvular heart disease at 73.3\% [21]. While patients with valvular heart disease were found to have a higher incidence of stroke, systemic embolism or bleeding than their counter-parts without significant valve disease, the interaction $\mathrm{p}$ value for the primary endpoint at 0.38 , was not significant and paralleled the overall study findings $[21,29]$.

\section{ENGAGE AF-TIMI 48 Trial}

Edoxaban is a direct anti-Xa inhibitor, studied in the ENGAGE AF-TIMI 48 trial, which examined the efficacy and safety of the drug at two separate fixed doses in patients with atrial fibrillation, against warfarin [22]. This was also a randomized double-blinded, double-dummy, multicenter trial. The primary end point of first stroke of systemic embolic event was higher in the warfarin group (1.8\%) than in the high dose edoxaban group taking 60mg daily (1.57\%). This difference was not significant. At $p<0.001$, the annual rate of hemorrhagic stroke was significantly lower in both high and low dose edoxaban group compared to warfarin. The trial showed that both regimens of edoxaban were non-inferior to warfarin for prevention of stroke and systemic embolism, with significantly lower rate of bleeding and death from cardiovascular causes. The only exception reported was the subgroup receiving high dose edoxaban, which experienced a higher rate of gastrointestinal bleeding.

The study did allow inclusion of patients with bioprosthetic heart valves and/or valve repair in the trial, but patients with mechanical heart valves and those with moderate to severe mitral stenosis were excluded. Patient with any other indications for anticoagulation besides AF were also excluded from the trial [30]. It is important to study the patient population with prosthetic valves, mild mitral stenosis, mitral regurgitation or aortic valve disease were enrolled in the ENGAGE AF-TIMI 48 trial, to assess outcomes of AF patients with valvular heart disease who were treated with edoxaban.

\section{CONCLUSION}

Patients with valvular heart disease, particularly with mitral stenosis and prosthetic valve, have an increased incidence of thromboembolism. Additionally, concomitant AF presents an increased risk in patients with valvular heart 
disease. Currently, for patients with valvular AF, including patients with mechanical valve and mitral stenosis, the standard of care remains VKA [15,31].

As demonstrated by the review of the trials and the post hoc analysis, patients with valvular heart disease were included in the trials. In some of these trials, this included patients with varying degrees of mitral regurgitation, history of mitral repair and bioprosthetic valve, and not all severities of mitral stenosis were a contraindication for these trials. Patients with valvular heart disease, despite an increased risk of embolic event, had similar outcomes to those patients without SVD in these trials for primary end points (Table 2) [21, 22, 28].

Warfarin, as shown in the RE-ALIGN trial, is better for thromboembolism risk reduction in mechanical valve when compared to dabigatran [25]. This may be due to the fact that the pathogenesis of thrombus formation is different in mechanical valves compared to that in AF. Without a study powered to successfully demonstrate non-inferiority and safety of NOAC compared to warfarin in anticoagulation of patients with prosthetic valves, NOAC should not be used in patients with prosthetic valves, particularly those with mechanical valve.

Given the background of the subanalysis of patients with valvular heart disease included in the trials, the time is right for randomized clinical trials for patients with SVD with AF on target specific oral anticoagulants powered for evaluation of their safety and efficacy in valvular AF patient.

\section{CONFLICT OF INTEREST}

The authors confirm that this article content has no conflict of interest.

\section{ABBREVIATIONS}

$\begin{array}{lll}\text { AF } & = & \text { Atrial Fibrillation } \\ \text { AVR } & = & \text { Aortic Valve Replacement } \\ \text { INR } & = & \text { International Normalized Ratio } \\ \text { NOAC } & = & \text { New Oral Anticoagulant } \\ \text { NVAF } & = & \text { Non-Valvular Atrial Fibrillation } \\ \text { MVR } & = & \text { Mitral Valve Replacement } \\ \text { SVD } & = & \text { Significant Valvular Disease } \\ \text { TIA } & = & \text { Transient Ischemic Attack } \\ \text { VAF } & = & \text { Valvular Atrial Fibrillation } \\ \text { VKA } & = & \text { Vitamin K Antagonist }\end{array}$

\section{ACKNOWLEDGEMENTS}

We would like to thank Dr. Richard C. Becker for his suggestions in writing and for reviewing this manuscript.

\section{REFERENCES}

[1] Go AS, Mozaffarian D, Roger VL, et al. Heart disease and stroke statistics-2014 update: a report from the American Heart Association. Circulation 2014; 129(3): e28-292.

[http://dx.doi.org/10.1161/01.cir.0000441139.02102.80] [PMID: 24352519]

[2] Deverall PB, Olley PM, Smith DR, Watson DA, Whitaker W. Incidence of systemic embolism before and after mitral valvotomy. Thorax 1968; 23(5): 530-6.

[http://dx.doi.org/10.1136/thx.23.5.530] [PMID: 5680237]

[3] Szekely P. Systemic embolism and anticoagulant prophylaxis in rheumatic heart disease. BMJ 1964; 1(5392): 1209-12. [http://dx.doi.org/10.1136/bmj.1.5392.1209] [PMID: 14120826]

[4] Morton JB, Sanders P, Vohra JK, et al. Effect of chronic right atrial stretch on atrial electrical remodeling in patients with an atrial septal defect. Circulation 2003; 107(13): 1775-82. [http://dx.doi.org/10.1161/01.CIR.0000058164.68127.F2] [PMID: 12665497]

[5] Kistler PM, Sanders P, Fynn SP, et al. Electrophysiologic and electroanatomic changes in the human atrium associated with age. J Am Coll Cardiol 2004; 44(1): 109-16.

[http://dx.doi.org/10.1016/j.jacc.2004.03.044] [PMID: 15234418]

[6] Wolf PA, Dawber TR, Thomas HE Jr, Kannel WB. Epidemiologic assessment of chronic atrial fibrillation and risk of stroke: the Framingham study. Neurology 1978; 28(10): 973-7.

[http://dx.doi.org/10.1212/WNL.28.10.973] [PMID: 570666] 
[7] Coulshed N, Epstein EJ, McKendrick CS, Galloway RW, Walker E. Systemic embolism in mitral valve disease. Br Heart J 1970; 32(1): 26-34. [http://dx.doi.org/10.1136/hrt.32.1.26] [PMID: 5417843]

[8] Fleming HA, Bailey SM. Mitral valve disease, systemic embolism and anticoagulants. Postgrad Med J 1971; $47(551): 599-604$. [http://dx.doi.org/10.1136/pgmj.47.551.599] [PMID: 5098918]

[9] Roy D, Marchand E, Gagné P, Chabot M, Cartier R. Usefulness of anticoagulant therapy in the prevention of embolic complications of atrial fibrillation. Am Heart J 1986; 112(5): 1039-43. [http://dx.doi.org/10.1016/0002-8703(86)90318-2] [PMID: 3776800]

[10] Genton E, Barnett HJ, Fields WS, Gent M, Hoak JC. XIV. Cerebral ischemia: the role of thrombosis and of antithrombotic therapy. Study group on antithrombotic therapy. Stroke 1977; 8(1): 150-75. [http://dx.doi.org/10.1161/01.STR.8.1.150] [PMID: 835152]

[11] Miyasaka Y, Barnes ME, Gersh BJ, et al. Secular trends in incidence of atrial fibrillation in Olmsted County, Minnesota, 1980 to 2000, and implications on the projections for future prevalence. Circulation 2006; 114(2): 119-25. [http://dx.doi.org/10.1161/CIRCULATIONAHA.105.595140] [PMID: 16818816]

[12] Flint AC, Banki NM, Ren X, Rao VA, Go AS. Detection of paroxysmal atrial fibrillation by 30-day event monitoring in cryptogenic ischemic stroke: the Stroke and Monitoring for PAF in Real Time (SMART) Registry. Stroke 2012; 43(10): 2788-90. [http://dx.doi.org/10.1161/STROKEAHA.112.665844] [PMID: 22871679]

[13] Kernan WN, Ovbiagele B, Black HR, et al. Guidelines for the prevention of stroke in patients with stroke and transient ischemic attack: a guideline for healthcare professionals from the American Heart Association/American Stroke Association. Stroke 2014; 45(7): $2160-236$. [http://dx.doi.org/10.1161/STR.0000000000000024] [PMID: 24788967]

[14] Fuster V, Rydén LE, Cannom DS, et al. American college of cardiology/American Heart Association task force on practice guidelines; European Society of Cardiology Committee for Practice Guidelines; European Heart Rhythm Association; Heart Rhythm Society. ACC/AHA/ESC 2006 Guidelines for the Management of Patients with Atrial Fibrillation: a report of the American College of Cardiology/American Heart Association Task Force on Practice Guidelines and the European Society of Cardiology Committee for Practice Guidelines (Writing Committee to Revise the 2001 Guidelines for the Management of Patients With Atrial Fibrillation): developed in collaboration with the European Heart Rhythm Association and the Heart Rhythm Society. Circulation 2006; 114(7): e257-354. [PMID: 16908781]

[15] January CT, Wann LS, Alpert JS, et al. American College of Cardiology/American Heart Association Task Force on Practice Guidelines. 2014 AHA/ACC/HRS guideline for the management of patients with atrial fibrillation: a report of the American College of Cardiology/American Heart Association Task Force on Practice Guidelines and the Heart Rhythm Society. J Am Coll Cardiol 2014; 64(21): e1-76.

[http://dx.doi.org/10.1016/j.jacc.2014.03.022] [PMID: 24685669]

[16] Camm AJ, Lip GY, De Caterina R, et al. ESC Committee for Practice Guidelines (CPG). 2012 focused update of the ESC Guidelines for the management of atrial fibrillation: an update of the 2010 ESC Guidelines for the management of atrial fibrillation. Developed with the special contribution of the European Heart Rhythm Association. Eur Heart J 2012; 33(21): 2719-47. [http://dx.doi.org/10.1093/eurheartj/ehs253] [PMID: 22922413]

[17] Patel MR, Mahaffey KW, Garg J, et al. ROCKET AF Investigators. Rivaroxaban versus warfarin in nonvalvular atrial fibrillation. N Engl J Med 2011; 365(10): 883-91. [http://dx.doi.org/10.1056/NEJMoa1009638] [PMID: 21830957]

[18] ROCKET AF Study Investigators. Rivaroxaban-once daily, oral, direct factor Xa inhibition compared with vitamin K antagonism for prevention of stroke and Embolism Trial in Atrial Fibrillation: rationale and design of the ROCKET AF study. Am Heart J 2010; 159(3): 340-347.e1.

[http://dx.doi.org/10.1016/j.ahj.2009.11.025] [PMID: 20211293]

[19] Ezekowitz MD, Connolly S, Parekh A, et al. Rationale and design of RE-LY: randomized evaluation of long-term anticoagulant therapy, warfarin, compared with dabigatran. Am Heart J 2009; 157(5): 805-10. [http://dx.doi.org/10.1016/j.ahj.2009.02.005] [PMID: 19376304]

[20] Lopes RD, Alexander JH, Al-Khatib SM, et al. ARISTOTLE Investigators. Apixaban for reduction in stroke and other ThromboemboLic events in atrial fibrillation (ARISTOTLE) trial: design and rationale. Am Heart J 2010; 159(3): 331-9. [http://dx.doi.org/10.1016/j.ahj.2009.07.035] [PMID: 20211292]

[21] Avezum A, Lopes RD, Schulte PJ, et al. Apixaban versus warfarin in patients with atrial fibrillation and valvular heart disease: findings from the Aristotle study. Eur Heart J 2014; 34(1).

[22] Giugliano RP, Ruff CT, Braunwald E, et al. ENGAGE AF-TIMI 48 Investigators. Edoxaban versus warfarin in patients with atrial fibrillation. N Engl J Med 2013; 369(22): 2093-104.

[http://dx.doi.org/10.1056/NEJMoa1310907] [PMID: 24251359]

[23] Connolly SJ, Ezekowitz MD, Yusuf S, et al. RE-LY Steering Committee and Investigators. Dabigatran versus warfarin in patients with atrial fibrillation. N Engl J Med 2009; 361(12): 1139-51. [http://dx.doi.org/10.1056/NEJMoa0905561] [PMID: 19717844]

[24] Ferreira J, Ezekowitz MD, Connolly SJ, et al. RE-LY Investigators. Dabigatran compared with warfarin in patients with atrial fibrillation and 
symptomatic heart failure: a subgroup analysis of the RE-LY trial. Eur J Heart Fail 2013; 15(9): 1053-61.

[http://dx.doi.org/10.1093/eurjhf/hft111] [PMID: 23843099]

[25] Eikelboom JW, Connolly SJ, Brueckmann M, et al. RE-ALIGN Investigators. Dabigatran versus warfarin in patients with mechanical heart valves. N Engl J Med 2013; 369(13): 1206-14. [http://dx.doi.org/10.1056/NEJMoa1300615] [PMID: 23991661]

[26] Christensen TD, Larsen TB. Dabigatran versus warfarin in patients with mechanical heart valves: comment. J Thromb Haemost 2014; 12(3): 424-5. [http://dx.doi.org/10.1111/jth.12497] [PMID: 24373331]

[27] Rivaroxaban for the prevention of stroke and Non-Central Nervous System (CNS) systemic embolism in patients with atrial fibrillation Advisory Committee Briefing Document FDA 2011.

[28] Breithardt G, Baumgartner H, Berkowitz SD, et al. ROCKET AF Steering Committee \& Investigators. Clinical characteristics and outcomes with rivaroxaban $v s$. warfarin in patients with non-valvular atrial fibrillation but underlying native mitral and aortic valve disease participating in the ROCKET AF trial. Eur Heart J 2014; 35(47): 3377-85.

[http://dx.doi.org/10.1093/eurheartj/ehu305] [PMID: 25148838]

[29] Granger CB, Alexander JH, McMurray JJ, et al. ARISTOTLE Committees and Investigators. Apixaban versus warfarin in patients with atrial fibrillation. N Engl J Med 2011; 365(11): 981-92.

[http://dx.doi.org/10.1056/NEJMoa1107039] [PMID: 21870978]

[30] Ruff CT, Giugliano RP, Antman EM, et al. Evaluation of the novel factor Xa inhibitor edoxaban compared with warfarin in patients with atrial fibrillation: design and rationale for the Effective aNticoaGulation with factor xA next GEneration in Atrial Fibrillation-Thrombolysis In Myocardial Infarction study 48 (ENGAGE AF-TIMI 48). Am Heart J 2010; 160(4): 635-41. [http://dx.doi.org/10.1016/j.ahj.2010.06.042] [PMID: 20934556]

[31] Nishimura RA, Otto CM, Bonow RO, et al. American College of Cardiology/American Heart Association Task Force on Practice Guidelines. 2014 AHA/ACC guideline for the management of patients with valvular heart disease: a report of the American College of Cardiology/American Heart Association Task Force on Practice Guidelines. J Am Coll Cardiol 2014; 63(22): e57-185. [http://dx.doi.org/10.1016/j.jacc.2014.02.536] [PMID: 24603191]

[32] Connolly SJ, Eikelboom J, Joyner C, et al. AVERROES Steering Committee and Investigators. Apixaban in patients with atrial fibrillation. N Engl J Med 2011; 364(9): 806-17.

[http://dx.doi.org/10.1056/NEJMoa1007432] [PMID: 21309657]

[33] Eikelboom JW, O'Donnell M, Yusuf S, et al. Rationale and design of AVERROES: apixaban versus acetyl-salicylic acid to prevent stroke in atrial fibrillation patients who have failed or are un-suitable for vitamin K antagonist treatment. Am Heart J 2010; 159(3): 53-348.

[34] Wallentin L, Yusuf S, Ezekowitz MD, et al. Efficacy and safety of dabigatran compared with warfarin at different levels of international normalised ratio control for stroke prevention in atrial fibrillation: an analysis of the RE-LY trial Lancet 376. England: Elsevier Ltd 2010; pp. 975-83.

[35] Edoxaban vs. Warfarin in subjects undergoing cardioversion of atrial fibrillation (ENSURE IN AF). Available from: http: //clinicaltrials.gov/show/NCT02072434

(C) Ahmad and Wilt; Licensee Bentham Open.

This is an open access article licensed under the terms of the Creative Commons Attribution-Non-Commercial 4.0 International Public License (CC BY-NC 4.0) (https://creativecommons.org/licenses/by-nc/4.0/legalcode), which permits unrestricted, non-commercial use, distribution and reproduction in any medium, provided the work is properly cited. 